\title{
Corrigendum: Superfast assembly and synthesis of gold nanostructures using nanosecond low-temperature compression via magnetic pulsed power
}

Binsong Li, Kaifu Bian, J. Matthew D. Lane, K. Michael Salerno, Gary S. Grest, Tommy Ao, Randy Hickman, Jack Wise, Zhongwu Wang \& Hongyou Fan

Nature Communications 8:14778 doi: 10.1038/ncomms14778 (2017); Published 16 Mar 2017; Updated 24 May 2017

In Fig. 5 of this Article, the image in the centre column for [111] incorrectly replicates the image above. The correct version of Fig. 5 appears below as Fig. 1 .

\footnotetext{
(c) This work is licensed under a Creative Commons Attribution 4.0 International License. The images or other third party material in this article are included in the article's Creative Commons license, unless indicated otherwise in the credit line; if the material is not included under the Creative Commons license, users will need to obtain permission from the license holder to reproduce the material. To view a copy of this license, visit http://creativecommons.org/licenses/by/4.0/
}

(C) The Author(s) 2017 

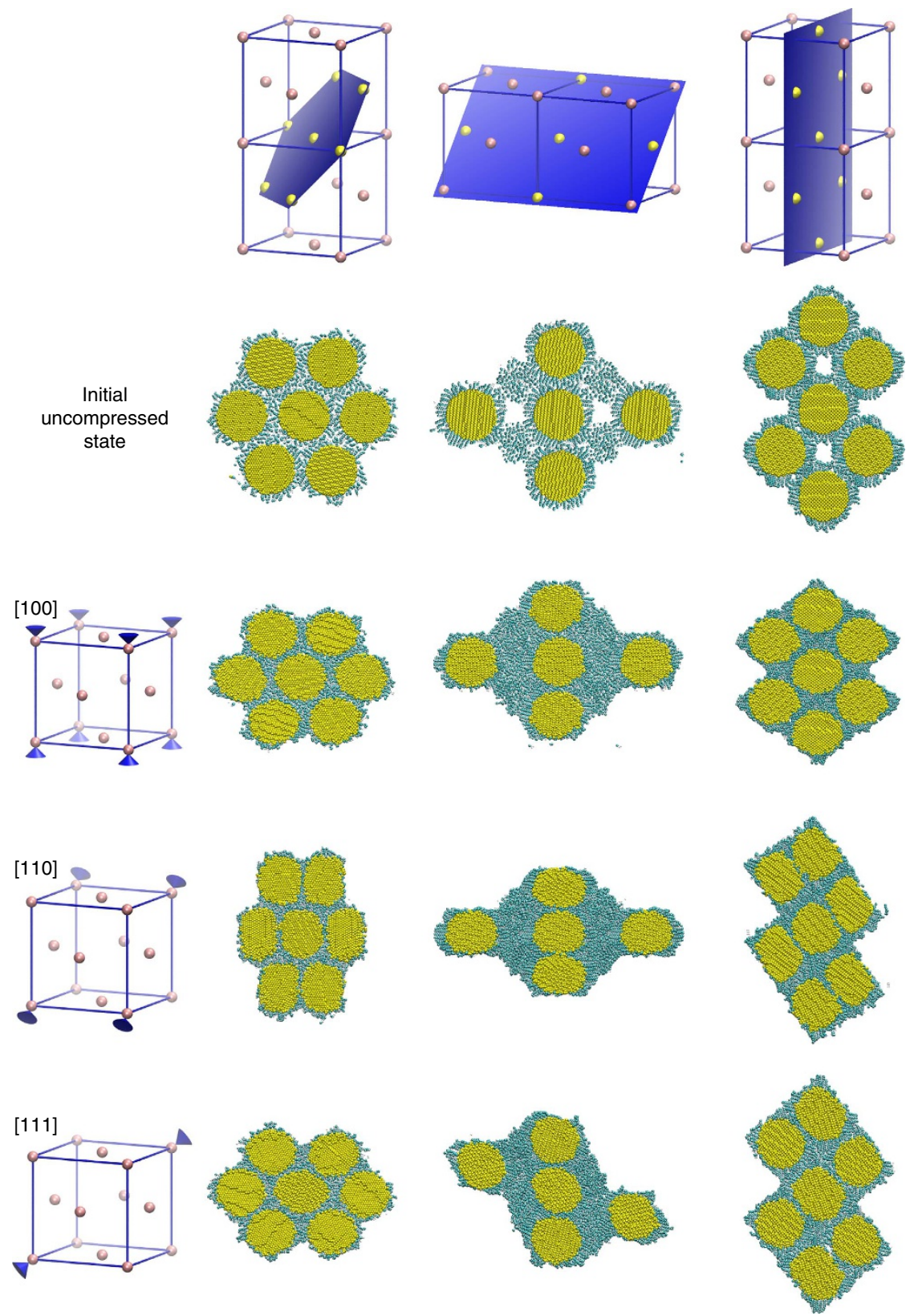

Figure 1 